A Supplement to the Catalogue of the Grace K. Babson Collection of the Works of Sir Isaac Newton and Related Material in the Babson Institute Library, Babson Park, Massachusetts Compiled by Henry P. Macomber. Pp. viii +91 . (Babson Park, Mass.: Babson Institute, 1955.) 4.90 dollars.

TN 1950 appeared the "Catalogue of the Babson 1 Collection of the Works of Sir Isaac Newton", an ordered description of an important Newton library, housed in Babson Park, Massachusetts (see Nature, $166,284 ; 1950)$. The present "Supplement", compiled by Mr. Henry Macomber, the curator of the Collection and associate compiler of the original catalogue, lists a number of items of all kinds-books, reprints, manuscripts, photostats, photographs, portraits and so on - which have accrued to the Collection since the first catalogue was issued.

There are a few early books of high importance, such as copies of Huygens's "Horologium Oscillatorium", Kepler's "Astronomia Nova", l'Hospital's "Analyse des Infiniment Petits" and Hooke's "Micrographia"; but many of the acquisitions are in the way of recent writings about Newton, including reprints and extracts from journals. There are also a number of items of minor interest, in the case of some of which the Newtonian interest tends to be remote, as, for example, Hollar's etching of the Royal Exchange, made in 1644, which is a charming work, and an odd Vol. 1 of a two-volume edition of Boswell's "Life of Samuel Johnson", published in Philadelphia in 1841 .

The work is produced uniformly with the original catalogue, all owners of which will certainly wish to acquire this supplement, which, incidentally, contains an errata list for the original volume.

E. N. DA C. ANDrade

Progress in Organic Chemistry

Edited by Prof. J. W. Cook. Vol. 3. (Progress Series.) Pp. viii +273 . (London: Butterworths Scientific Publications; New York: Academic Press, Inc., 1955.) 45s.

THE third volume of this useful series certainly continues to enhance its reputation for providing up-to-date reviews of live topics. The first survey, on the total synthesis of steroids, by Dr. J. W. Cornforth, is that rarity-a comprehensive account of a complex subject written with clarity, modesty and humour. Every synthetic route is discussed and the story of this triumph of organic chemistry makes stimulating and enjoyable reading.

Since Prof. W. Baker's 1945 Tilden Lecture on non-benzenoid aromatic compounds, important new advances have been made in this field, and it is fitting that Prof. Baker (with Dr. J. F. W. McOmie) contributes to the volume a chapter on these compounds, which fully incorporates the recent work. 'This account is complemented by the succeeding chapter on the fulvenes, by Prof. E. D. Bergmann, which is a very full description of these interesting compounds.

'Ihe advantages of organo-lithium compounds over the more conventional Grignard reagents have been gaining recognition for some time. The chapter on organic compounds of lithium, by Prof. E. A. Braude, is therefore particularly timely and useful, and achieves a nice blend of practical and theoretical considerations. The pharmacological properties of reserpine have focused much recent attention on the yohimbine group of alkaloids. In the final chapter, on the indole alkaloids, Profs. V. Boekelheide and V. Prelog describe the modern investigations on this group and on other indole alkaloids, the unusual fine structures of which have been recently unravelled (the corynantheine, cinchonamine and erythrina alkaloids).

R. A. Raphate

\section{An Index of Mineral Species and Varieties Arranged Chemically}

With an Alphabetical Index of accepted Mineral Names and Synonyms. By Dr. Max H. Hey. Second, revised edition. Pp. xxiv +728 . (London: British Museum (Natural History), 1955.) 60s.

I' $\mathrm{T}$ is five years since the British Museum (Natural 1 History) issued the "Index of Mineral Species and Varieties", compiled by Dr. M. H. Hey (see Nature, 167, 873; 1951). In the interval, much progress has been made in mineral chemistry, and the new edition of this valuable work of reference has been revised throughout by Dr. Hey. New information, up to March 1955, has been incorporated in the text, and last-minute addenda and corrections, up to April 1955, have been printed on four pages at the end of the book. The only other change is the addition of a "Pronouncing Index of Accepted Mineral Names", which has been included in an attempt to establish uniformity of pronunciation of mineral names in English-speaking countries-not an easy task; this index occupies sixty-six pages. Scientific libraries not already owning a copy of this work will no doubt welcome the opportunity to purchase it in its revised form.

\section{Genetics in the Atomic Age}

By Dr. Charlotte Auerbach. Pp. vii +106. (Edinburgh and London: Oliver and Boyd, Ltd., 1956.) $8 s .6 d$. net.

A GROWING number of persons are beçoming A concerned about the genetic consequences of the exposure of human populations to radiation, but few are well informed about the scientific principles underlying the question. This little book has the timely purpose of helping to fill this gap for the non-biologist, and is admirably designed to do so. It is a model of lucidity and conciseness. Dr. Charlotte Auerbach, herself a first-rank teacher and investigator in genetics, presents the facts necessary for a grasp of the radiation question without recourse to ratios, equations or technical terms. Mutations, their effects, their hereditary transmission, and their evolutionary role are discussed in four chapters ; the final two deal with the production of mutations by radiation and with facts relevant particularly to the human problem, and examine the nature of the consequences that future generations of mankind may suffer through exposure of the present ones to radiation.

The drawings by Miss I. G. Auerbach are most, helpful, and have an original charm of their own. An appendix of scientific terms, not themselves used in the text but describing facts and ideas explained there, will assist readers who go on to more technical writings in genetics.

This book will do much to give its readors the knowledge necessary to judge wisely the genetic hazard due to radiation. Its obvious power to stimulate interest would make it a valuable addition to any biology class-room shelf or school library. 